\title{
PERFIL DE MULHERES SOB PRIVAÇÃO DE LIBERDADE: ASPECTOS SOCIODEMOGRÁFICOS, OCUPACIONAIS E CRIMINAIS
}

\author{
Wallison Pereira dos Santos \\ Fernanda Beatriz Dantas de Freitas \\ Gigliola Marcos Bernardo de Lima \\ André Pereira de Farias Neto
}

\begin{abstract}
RESUMO
Levantar o perfil sociodemográfico, ocupacional e criminal de mulheres sob privação de liberdade no estado da Paraíba consiste em um estudo exploratório e descritivo, com abordagem quanti-qualitativa do tipo "Estudo de Caso", realizado no Centro de Reeducação Maria Julia Maranhão, na Paraíba, com a participação de 219 mulheres. Os dados foram obtidos por intermédio de uma entrevista semiestruturada e para análise dos dados foi realizado uma comparação entre os cenários estudados e a literatura pertinente. Após a obtenção de dados, por meio de questionário, as informações foram convertidas em quadros e tabelas. A pesquisa possibilitou constatar que o perfil das detentas é similar em todos os cenários. Portanto, o perfil de mulheres, sob privação de liberdade, se apresenta como sendo uma mulher negra, de baixa escolaridade, baixa condição financeira, solteira e com idade entre 22 e 25 anos.
\end{abstract}

\section{PALAVRAS-CHAVE}

Estrutura demográfica. Prisões. Atenção integral à saúde da mulher. Comportamento social. Justiça criminal.

\section{INTRODUÇÃO}

As primeiras notícias da criminalidade feminina estão relacionadas à bruxaria e a prostituição, condutas contrárias ao papel pré-determinado à mulher pelas sociedades da época, uma vez que ela deveria se restringir ao âmbito do espaço privado do lar. O discurso criminológico clássico, aqui emergente, teve o foco na ilegalidade do ato crime, classificando-o e determinando punições específicas para cada tipo. A mulher criminosa teve tanto destaque quanto o homem, sendo observadas diferenciações apenas relacionadas à tipicidade do crime em si, por exemplo, à prostituição atribuída à mulher. Neste momento, os códigos apresentavam crimes referentes à vagabundagem, à homossexualidade e à prostituição. E é a figura da prostituta como degenerada moral e criminosa que pode ser considerada, nes-

I. Acadêmico do Curso de Bacharelado em Enfermagem, Pesquisador do Programa Institucional de Bolsas da Iniciação Científica - PIBIC, Universidade Federal de Campina Grande, Campus Cuité (PB), Brasil. E-mail: wallisons852@gmail.com. Telefone: (83)99971-4859.

II. Acadêmica do Curso de Bacharelado em Enfermagem, Universidade Federal de Campina Grande, Campus Cuité (PB), Brasil.

III. Enfermeira, Professora Doutora, Universidade Federal de Campina Grande, Campus Cuité (PB), Brasil.

IV. Historiador, Professor Doutor, Programa de Pós-Graduação em Informação e Comunicação em Saúde pelo Instituto de Comunicação e Informação Científica e Tecnológica em Saúde (Icict) - Fundação Oswaldo Cruz (RJ), Brasil. 
ta análise, a primeira figura feminina de destaque nos discursos criminológicos ${ }^{1}$.

A beleza também sempre teve um papel relevante na construção dos estigmas criminosos. No caso dos crimes ligados à sexualidade, como a prostituição, a beleza era considerada definidor para medir a periculosidade da mulher. Em outros casos, a aparência física era utilizada para minimizar situações em que a mulher era autora de crimes $^{2}$.

O Código Penal Brasileiro apresenta o ideal de mulher honesta e a criminalidade decorrente de ações contrárias as que não se espera que ela pratique. Da mesma forma, a figura da criminosa masculinizada permanece viva no imaginário popular e de alguns magistrados. Essa constitui-se em uma figura, calcada pelo discurso criminológico positivista, como detentor de uma periculosidade nata, uma anormalidade sem possibilidade de tratamento, tanto quanto a figura da prostituta. Para este discurso, a prostituta é uma mulher dada a vícios, a paixões, à preguiça, com um alto grau de reincidência, pois não usufruiria da prisão para se reeducar, preferindo continuar com uma vida de imoralidade, não se limitando apenas à prostituição e à troca constante de amantes, mas cometendo diversos outros delitos3.

Assim, figuras femininas foram circunscritas ao longo da história por diversos saberes e práticas. É sabido que, por muitos séculos, em comum elas mantiveram a docilidade, a fragilidade, a dependência, a maternidade e a vocação para a família, sendo inaceitável o comportamento divergente destes. No caso das mulheres autoras de delitos, estas ainda ocupam

\section{MATERIAIS E MÉTODOS}

Trata-se de um estudo de caso com abordagem quanti-qualitativa. Os estudos de caso têm várias aplicações. Assim, é apropriado para pesquisadores individuais, pois dá a oportunidade para que um aspecto um espaço de oposição à figura feminina aceita socialmente ou, para utilizar-se de um enunciado jurídico apresentado até os dias atuais, na codificação brasileira, a muIher criminosa está em oposição à figura da mulher honesta ${ }^{1}$.

Os impactos das construções culturais relacionadas ao feminino e ao masculino se tornam nítidos na análise das complexidades que envolvem o mundo do crime, pois, historicamente, mulheres e homens não estiveram envolvidos da mesma forma nas práticas ilícitas. A criminalidade sempre esteve fortemente associada aos homens, devido, principalmente, a associação do sexo masculino à violência, virilidade e transgressão, frutos de produções discursivas que reforçam habilidades masculinas associadas a essas práticas e características. Contudo, essa realidade está em transição, pois na sociedade contemporânea, há o aumento da incidência de mulheres envolvidas no cometimento de atos ilícitos e práticas de violência4.

A criminologia vive hoje seu terceiro momento, indicado na década de 1970, quando demostra pender para uma abordagem epistemológica crítica. Para este autor, a mulher criminosa define-se a partir das circunstâncias que a levaram aos atos criminosos e não mais a partir de seu desvio, ou de sua posição passiva sendo, portanto, um sujeito emancipado que não se submete ao poder do patriarcado nem ao do direito penal ${ }^{1}$.

Dessa forma, o presente estudo objetivou levantar o perfil sociodemográfico, ocupacional e criminal de mulheres encarceradas no estado da Paraíba.

de um problema seja estudado em profundidade, dentro de um período de tempo limitado. Além disso, parece ser apropriado para investigação de fenômenos, quando há uma grande variedade de fatores e rela- 
cionamentos, que podem ser diretamente observados e não existem leis básicas para determinar quais são importantes ${ }^{5}$.

A pesquisa qualitativa responde a questões muito particulares. Ela se preocupa, nas ciências sociais, com um nível de realidade que não pode ser quantificado. Ou seja, ela trabalha com o universo de significados, motivos, aspirações, crenças, valores e atitudes, o que corresponde a um espaço mais profundo das relações, dos processos e dos fenômenos que não podem ser reduzidos à operacionalização de variáveis ${ }^{6}$.

A pesquisa quantitativa, que tem suas raízes no pensamento positivista lógico, tende a enfatizar o raciocínio dedutivo, as regras da lógica e os atributos mensuráveis da experiência humana. Por outro lado, a pesquisa qualitativa tende a salientar os aspectos dinâmicos, holísticos e individuais da experiência humana, para apreender a totalidade no contexto daqueles que estão vivenciando o fenômeno?.

O conjunto de dados quantitativos e qualitativos, porém, não se opõem. Ao contrário, se complementam, pois a realidade abrangida por eles interage dinamicamente, excluindo qualquer dicotomia ${ }^{6}$.

O presente estudo teve como cenário de investigação o Centro de Reeducação Maria Julia Maranhão, detentor do maior percentual de mulheres presas e ainda o maior presídio em extensão do estado da Paraíba, localizado em João Pessoa, capital do estado. Na investigação, foi realizado o levantamento do perfil social, demográfico, financeiro e pessoal de muIheres, sob privação de liberdade do Estado da Paraíba. Foram então elencadas as principais características das entrevistadas, expressas por meios dos dados coletados.

O universo foi constituído por 400 mulheres, sendo 300 em regime fechado e 100 em regime semiaberto. Para participar da pesquisa, se fez necessário que a detenta tivesse idade maior de 18 (dezoito) anos, estivesse sob regime de reclusão fechado e fosse de sua livre vontade a participação.

O instrumento para coleta de dados foi um questionário autoaplicável e dividido em duas partes: dados sociais e dados criminais. Antes da aplicação do questionário, o pesquisador explicou a finalidade da pesquisa e fez o convite para a participação entre as detentas, em 19 (dezenove) celas. A coleta aconteceu entre os meses de Maio e Agosto de 2012, abrangendo 219 participantes, perfazendo uma amostra de $64,6 \%$ do universo, dos quais o número total é 339 mulheres em regime fechado e com idade acima de 18 anos. Neste estudo, a amostra correspondeu a 219 mulheres $(\mathrm{N}=219)$.

$\mathrm{Na}$ análise dos dados obtidos, estes foram comparados com informações do cenário mundial, nacional e estatal. Para os dados mundiais utilizou-se o referencial do Centro Internacional de Estudos em Prisões (ICPS). Já quanto aos dados nacionais e estaduais foram utilizadas fontes como o INFOPEN - Sistema de Integrado de Informações Penitenciárias e da administração penitenciária do estado da Paraíba. O estudo foi submetido ao Comitê de Ética em Pesquisas da Fundação Oswaldo Cruz. Após a aprovação pelo parecer favorável de número 272/11 e CAEE: 0289.0.031.000.11, foi iniciada a pesquisa.

mação Penitenciária Brasileira. Os dados foram dispostos em três categorias: dados sociodemográficos, ocupacionais e criminais, posteriormente tabulados em forma de tabelas. 


\section{Dados sociodemográficos}

A tabela 1 apresenta o montante de mulheres sob privação de liberdade em nível mundial, nacional e estadual. Dados mundiais revelam que no mundo existem 660.000 mulheres privadas de liberdade. No Brasil, esse número é de 37.380 e no estado da Paraíba representa 621 mulheres encarceradas. Já a amostra do estudo de caso da pesquisa, realizada no Centro de Reeducação Maria Júlia Maranhão, apresenta $64,4 \%$ do total de presidiárias em todo o estado, fato esse justificado por se tratar do maior presídio em população feminina e em espaço físico da Paraíba.

O aumento do número de mulheres encarceradas cresce progressivamente.
Observa-se, a partir do ano de 2000, um aumento de cerca de 50\% nos últimos 15 anos. Número alarmante quando comparado ao crescimento do sexo masculino. O quantitativo de mulheres sob privação de liberdade geralmente está entre 2 e $9 \%$ da população total prisional mundial. O número mais acentuado foi observado em Hong Kong-China, representando 19\% desse total. Esse aumento surpreendente do número de detentas deve levar a rápidas estratégias políticas de todos os países, uma vez que o encarceramento feminino tem um alto custo financeiro e social. Por outro lado, o uso desse sistema prisional não apresenta melhoria na segurança pública 8 .

Tabela 1 - População no mundo, no Brasil, na Paraíba e no Centro de reeducação Maria Júlia Maranhão de mulheres sob privação de liberdade. Cuité(PB), Brasil, 2017.

\begin{tabular}{|c|c|c|c|}
\hline Mundial & Nacional & Estadual & Amostra \\
\hline 660.000 & 37.380 & 621 & 400 \\
\hline
\end{tabular}

Fonte: ICPS, 2015; INFOPEN, 2014; PARAÍBA, 2016; LIMA, 2013.

Paralelos à realidade prisional mundial feminina, os números de crescimento populacional prisional do Brasil apontam um crescimento de $567 \%$ no período de 2000 a 2014, valor duas vezes maior que o aumento da população carcerária masculina. Esses percentuais corroboram com dados de nível mundial 9 .

O crescimento da população carcerária na Paraíba segue a tendência nacional, uma vez que pode ser verificado no estado da Paraíba um aumento de 238,8\% entre os anos de 2011 e $2016^{10}$ Esse crescimento da população carcerária ocorre de forma progressiva e rápida, sem que haja melhoria de infraestrutura compatível com essa acelerada expansão populacional. Como consequência, vem a superlotação carcerária em detrimento da limitação especial nos presídios ${ }^{11}$. Quanto ao perfil sociodemográfico, a tabela 2 retrata características das mulheres sob privação de liberdade.

Tabela 2 - População no mundo, no Brasil, na Paraíba e no Centro de reeducação Maria Júlia Maranhão de mulheres sob privação de liberdade. Cuité(PB), Brasil, 2017.

\begin{tabular}{c|c|c|c|}
\hline $\begin{array}{c}\text { Características } \\
\text { sociodemográficas }\end{array}$ & Brasil & Paraíba & Dados da pesquisa \\
\hline Faixa etária & 18 a 24 anos - 27\% & 19 a 29 anos - 26\% & 21 a 25 anos - 25\% \\
\hline Estado Civil & Solteira - 57\% & Soltira - 64\% & Solteira - 63\% \\
\hline Cor da pele & Negra - 68\% & Negra - 83\% & Parda - 51\% \\
\hline Escolaridade & Fund. Inc. - 50\% & Fund. Inc. - 50\% & Fund. Inc. 34\% \\
\hline
\end{tabular}

Fonte: ICPS, 2015; INFOPEN, 2014; PARAÍBA, 2016; LIMA, 2013. 
Informações nacionais e estaduais dão conta que o perfil sociodemográfico da mulher encarcerada é expressivamente jovem com idade entre 18 a 29 anos, solteira, negra e com o ensino fundamental incompleto. Já os dados do estudo de caso, diferem apenas no quesito cor de pele, traduzindo uma mulher de cor parda, cerca de $51 \%$ da amostra.

A faixa etária, observada no cenário nacional, é de mulheres jovens, com idade abaixo de 25 anos, período extremamente ativo na funcionalidade econômica para o país 9 . No estado da Paraíba a idade média das mulheres, privadas de liberdade, gira em torno de 24 anos, indo de encontro com a realidade nacional apresentada ${ }^{10}$.

A pesquisa realizada no Centro de Reeducação Maria Júlia Guimarães apresenta que $63 \%$ das mulheres encarceradas são solteiras, revelando uma hegemonia, tanto no cenário estadual, quanto no cenário nacional.

Muitas mulheres se remetem à condição de estado civil formal, não abarcando a relação não oficializada como uma forma de estado civil. Além desse fator, observa-se que, após a prisão, ocorre o abandono dos parceiros, seja homem ou mulher, evidenciando uma correlação com a sociologia de ingratidão machista do percorrer dos meandros da afetividade feminina ${ }^{11}$.

Dados nacionais apontam a cor negra como mais frequente entre as encarceradas, indo de encontro com as informações do estado da Paraíba, no ano de 2016 , em que $83 \%$ das mulheres se consideravam como negras 9 . Isso remete a analogia do cidadão com comportamentos inadequados como sempre sendo de cor negra, seja no âmbito nacional ou estadual. Contudo, dados da amostra da pesquisa apontam a categoria parda como mais presente, contrapondo as informações estaduais e nacionais. No entanto, as categorias raciais são modificáveis, mutáveis e variáveis, principal- mente quando auto-atribuídas ${ }^{11}$.

O baixo grau de escolaridade foi observado, tanto no cenário nacional, quanto estadual e expressado na amostra da pesquisa. Geralmente, esse dado é associado a baixas condições socioeconômicas, remete ainda ao maior índice de criminalidade. Porém, essa espécie de associação deve ser analisada de maneira cuidadosa, uma vez que resulta em estigma ao dar a entender que indivíduos de baixo nível escolar são mais propensos à criminalidade ${ }^{11}$.

Pode-se observar que houve um alinhamento de informação que não variava, mesmo que o cenário de mensuração seja nacional ou estadual e ainda na amostra da pesquisa, reafirmando que o perfil da mulher, submetida ao cárcere, é jovem, solteira, negra e de baixa escolaridade 9 .

\section{Dados ocupacionais}

É imperioso destacar que $70 \%$ das mulheres, privadas de liberdade no Brasil, não tinham ocupação antes da prisão, enquanto que em dados disponibilizados pelo Governo do Estado da Paraíba em 2016, no que diz respeito ao âmbito estadual, revelam números ainda maiores, chegando a $85 \%$ de mulheres que não tinham ocupação antes do encarceramento, conforme tabela 3.

A não ocupação é considerada um fator contribuinte para o aumento da inserção da mulher no mundo do crime, tendo em vista que essa falta de ocupação dessas mulheres supracitadas as tornam susceptíveis ao crime considerando que, por não possuírem um vínculo trabalhista, passavam a enxergar no crime uma oportunidade de conseguir dinheiro fácil e rápido ${ }^{12}$.

Conforme os dados, $70 \%$ das mulheres em situação de privação de liberdade tinham ocupação antes da prisão, uma vez que consideram ocupação os afazeres domésticos. Porém, as ocupações de baixa qualificação com salários desproporcionais a tais ocupações, também podem 
contribuir para inclusão da mulher na marginalidade. Devido aos baixos salários, essas mulheres viam a necessidade de encontrar algo que lhes oferecesse uma renda extra para que assim pudessem custear suas famílias. Encontram, portanto, no crime uma espécie de saída de emergência ${ }^{13,11}$.

No tocante à ocupação dentro da prisão, há números altos de mulheres exercendo alguma ocupação no âmbito penitenciário, sendo $75 \%$ no Brasil e $92 \%$ na Paraíba. O que evidencia que está ocorren- do uma reeducação em uma quantidade significativa de detentas, tornando dessa maneira mais viável sua ressocialização, o que é de fundamental importância, considerando que a finalidade da Lei de Execução Penal é produtiva e educativa 9,10 .

Dados do cenário do estudo comprovam estatísticas de uma realidade bem diferente da discutida, no que se diz respeito ao contexto do Brasil e da Paraíba, evidenciando que $80 \%$ das mulheres em privação de liberdade não exercessem nenhuma espécie de atividade dentro da prisão.

Tabela 3 - Distribuição de dados ocupacionais nacionais, estatais e da amostra da pesquisa. Cuité (PB), Brasil, 2017.

\begin{tabular}{|c|c|c|c|}
\hline Características Ocupacionais & Brasil & Paraíba & Dados da pesquisa \\
\hline Ocupação antes da prisão & Não - 70\% & Não - 85\% & Sim - 70\% \\
\hline Ocupação dentro da prisão & Sim - 75\% & Sim - 95\% & Não - 80\% \\
\hline
\end{tabular}

Fonte: INFOPEN, 2014; PARAÍBA, 2016; LIMA, 2013.

Esse número reduzido de mulheres com ocupação na prisão é visto como uma dificuldade de reinserção social para essas mulheres, tendo em vista que grande parte da população carcerária feminina demostra interesse em desenvolver atividades de ocupação laboral. Esse déficit de oportunidade para essas mulheres acaba por inviabilizar a reiteração social delas, bem como retira-lhes a esperança de um futuro melhor, com uma perspectiva de emprego fora da prisão, depois de cumprir sua pena ${ }^{11,14}$.

\section{Dados Criminais}

As informações criminais das muIheres, sob privação de liberdade, dão conta que, quanto ao tipo de regime, cerca de $80 \%$ estão em regime fechado. Já a tipologia criminal é expressivamente notável, em todos os cenários analisados, que o tráfico de entorpecentes é o mais comumente abordado com um número de $77 \%$. Já quanto ao total de pena em anos, a ser cumprido pelas detentas, é possível observar que uma grande parcela ainda não foi julgada, $61 \%$ como indicado na tabela 4 .

Tabela 4 - Distribuição de dados criminais nacionais, estatais e da amostra da pesquisa. Cuité (PB), Brasil, 2017.

\begin{tabular}{|c|c|c|c|}
\hline Características criminais & Brasil & Paraíba & Dados da pesquisa \\
\hline Tipo de regime & Fechado - $44,7 \%$ & Fechado - $82,7 \%$ & Provisório - $64 \%$ \\
\hline Tipo de crime cometido & Tráfico - 68\% & - & Tráfico - $77 \%$ \\
\hline Total de anos da pena & 4 a 8 anos - 35\% & 8 a 15 anos - 18\% & Não julgadas - $61 \%$ \\
\hline
\end{tabular}

Fonte: INFOPEN, 2014; PARAÍBA, 2016; LIMA, 2013. 
Toda população feminina, privada de liberdade do Brasil, 44,7\% dela encontra-se em regime fechado. Essas informações corroboram com estudo já realizado, o qual apresenta que no Centro de Reeducação Maria Julia Maranhão, 64\% dessas mulheres estão em regime provisório. Esses achados podem representar que um dos motivos para a superlotação é o não julgamento, ocasionando dessa maneira condições de habitação precárias e, consequentemente, um fator desfavorável para a saúde dessas presas 9,11 .

Em relação ao tipo de crime cometido, correspondem a $68 \%$ dos crimes pratica- dos pelas mulheres, privadas de liberdade no país, o tráfico de drogas 9 . O maior índice de crimes cometidos por essas mulheres encarceradas, referente ao Centro de Reeducação Maria Julia Maranhão, também é por tráfico de drogas $(61 \%)^{11}$.

A maioria das mulheres entra no mundo do crime através do tráfico de drogas. Destaca-se que muitas dessas mulheres atuam no tráfico, na sua maioria como coadjuvante e, muitas vezes, por influência de seus próprios companheiros já envolvidos com o tráfico ${ }^{15}$. Sendo elas na grande parte das vezes abandonadas por esses parceiros afetivos, depois de aprisionadas.

\title{
CONSIDERAÇÕES FINAIS
}

O presente estudo revelou que o perfil de mulheres, sob privação de liberdade do estado da Paraíba, consiste em uma mulher jovem entre 21 a 25 anos, solteira ou com união não oficial, de cor parda, de baixa condição financeira, escolaridade inferior ao segundo grau. A maioria não possuía ocupação antes da prisão e é ré primária. Como principal crime cometido tem-se o tráfico de entorpecentes. Estão sob regime fechado de forma provisória, aguardando ainda o

julgamento e não possuem ocupação dentro do local de aprisionamento.

Após a obtenção das informações no Centro de Reeducação Maria Júlia Maranhão e comparação com cenário mundial, nacional e estatal percebe-se que o perfil socioeconômico, ocupacional e criminal é equivalente. Conhecer o público sob privação de liberdade é importante para o planejamento de ações e estratégias para essa população.

\section{PROFILE OF WOMEN UNDER LIBERTY DEPRIVATION: REGARDING SOCIODEMOGRAPHIC, OCCUPATIONAL AND CRIMINAL ASPECTS}

\begin{abstract}
To raise the sociodemographic, occupational and criminal profile of women deprived of their liberty in the Paraíba state and to correlate with the worldwide, national and state data. An exploratory and descriptive study, with a quantitative-qualitative approach of the "Case Study" type, carried out at the Maria Julia Maranhão Reeducation Center in Paraíba, with the participation of 219 women, data were obtained through a semi-structured interview and to analyze the data, a comparison was made between the scenarios studied and the relevant literature. After obtaining data through a questionnaire, the information was converted into charts and tables. The research made it possible to verify that the profile of detainees is similar in all scenarios. Therefore the profile of women deprived of their liberty presents themselves as being a black woman, of low education, low financial condition, single and aged between 22 and 25 years.
\end{abstract}




\section{revista de NOVA
ciências da saúde ESPERANÇA}

\section{REFERÊNCIAS}

1 Barcinski. Mulheres no tráfico de drogas: a criminalidade como estratégia de saída da invisilidade social feminina. Contextos Clínic [periódico na internet] . 2012 [acesso em 12 Jun. 2017];5(1): 9 p. Disponível em: http://pepsic.bvsalud.org/pdf/cclin/v5n1/v5n1a07.pdf.

2 Neto HHC, Borges PCC. A mulher e o direito penal brasileiro: entre a criminalização pelo gênero e a ausência de tutela penal justificada pelo machismo. Rev Estudos Jurídicos [periódico na internet]. 2013 [acesso em 13 Jun. 2017];17(25): 20 p. Disponível em: https://ojs.franca.unesp.br/index.php/ estudosjuridicosunesp/article/view/927.

3 Lombroso C, Ferrero G. Criminal Woman, the Prostitute, and the Normal Woman. Durham: Duke University; 2004.

4 Marangoni SR, Oliveira MLF. Fatores desencadeantes do uso de drogas de abuso em mulheres. Texto \& contexto enferm [periódico na internet]. 2013 [acesso em 10 Jun. 2017];22(3): 8 p. Disponível em: http:// www.scielo.br/pdf/tce/v22n3/v22n3a12.pdf.

5 André M. O que é um estudo de caso qualitativo em educação? Rev FAEEBA [periódico na internet]. 2013 [acesso em 15 Jun. 2017];22(40): 8 p. Disponível em: https:// www.revistas.uneb.br/index.php/faeeba/ article/view/753

6 Minayo MCS. Pesquisa social. Teoria, método e criatividade. Petrópolis: Vozes; 2010.

7 Ludwing ACW. Métodos de Pesquisa em educação. Rev Temas em educação [periódico na internet]. 2014 [acesso em 18 Jun. 2017];23(2):19 p. Disponível em: http:// www2.marilia.unesp.br/revistas/index.php/ educacaoemrevista/article/view/5077
VOLUME 16 - NÚMERO 1 - ABR/2018

ISSN IMPRESSO 1679-1983 ISSN ELETRÔNICO 2317-7160
8 Centro Internacional De Estudos Prisionais. Institute for Criminal Policy Research. 2013. 9 Brasil. Ministério da Justiça. Levantamento de Informações Penitenciárias. Brasília, DF, 2014. 42 p.

10 Administração Penitenciária. Governo da Paraíba. 2014.

11 Lima GMB. A vida de Mulheres na prisão: legislação, saúde mental e superlotação em João Pessoa - PB. 2013. 124 f. Tese (Doutorado em Ciências na área de Saúde Pública)-Fundação Oswaldo Cruz, Rio de Janeiro, 2013.

12 Ferreira CA. Análise pericial do padrão de consumo de álcool em policiais e seus fatores de risco. Ciênc saúde coletiva [periódico na internet]. 2013 [acesso em 15 Jun. 2017];5(1): 18 p. Disponível em: http://www. scielo.br/pdf/csc/v16n8/a07v16n8.pdf.

13 Smyth KB, Pohlig RT, Bucurescu G. Female children with incarcerated adult family members at risk for lifelong neurological decline. Health care women int [periódico na internet]. 2016 [acesso em 18 Jun. 2017];37(7):14 p. Disponível em: https:// www.ncbi.nlm.nih.gov/pubmed/26788781

14 Farooq R, Emerson LM, Keoghan S, Adamou M. Prevalence of adult ADHD in an all-female prision unit. Irish Journal of Psychological Medicine [periódico na internet]. 2016 [acesso em 12 Jun. 2017];8(2):6 p. Disponível em: https://www.ncbi.nlm.nih. gov/pubmed/26650925.

15 Castello C. Woman and mother in prision, a difficult reality. Soins pédiatr puéric [periódico na internet]. 2015 [acesso em 18 Jun. 2017];1(28): 3 p. Disponível em: https:// www.ncbi.nlm.nih.gov/pubmed/26573399 